\title{
Salon
}

\section{Misrepresentation of science undermines HIV prevention}

$\mathrm{T}$ he injection of illegal drugs remains a driving factor in the HIV/AIDS pandemic. Although a large body of scientific evidence supports the application of prevention initiative, such as needle exchanges and methadone maintenance, these programs remain controversial and coverage of such programs remains low. A report by the Global HIV Prevention Working Group estimates that only $8 \%$ of injection drug users globally have access to HIV prevention services the lowest rate for any group highly vulnerable to HIV/AIDS. ${ }^{1}$ However, policies that are known to contribute to HIV transmission, such as the mass incarceration of nonviolent drug offenders, continue to receive support. Sadly, these trends persist due to the politicization and misrepresentation of science in this area.

Unfortunately, this pattern has been observed across several domains of public health. For example, there has been concern that the development of evidence-based health policy is being compromised by the politicization of science and efforts by corporations and lobby groups to undermine research that threatens profits or offends moral positions. In the United States more than 5000 scientists recently signed a statement demanding that the Bush administration cease from misrepresenting research. ${ }^{2}$ Mirroring the now infamous efforts of the tobacco industry to distort science, various corporations have gone to great lengths to denounce the notion of global warming. According to a 2007 report by the Union of Concerned Scientists, ExxonMobil provided more than \$16 million between I998 and 2005 to over 40 organizations that undertook efforts to undermine the science specific to global warming. ${ }^{3}$ The methods used to discredit science have become more diverse and have included funding seemingly independent scientific organizations, quasi-journalist outlets and public relations firms, and lob-

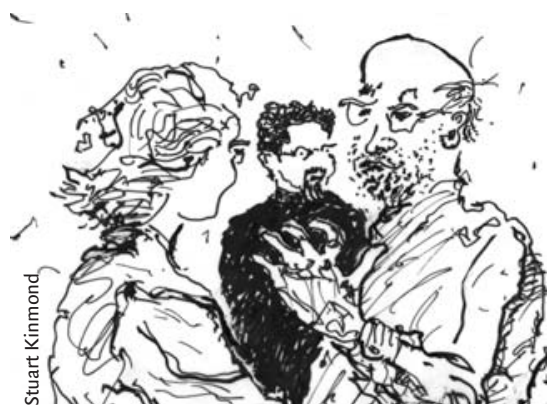

bying for political appointments to promote special interests.

Since the HIV pandemic is among the world's greatest public health challenges, it is important to consider how similar forces have worked to undermine HIV prevention efforts. Although those who have sought to prioritize abstinence over condom distribution have been widely criticized, recent events suggest that HIV prevention programs for injection drug users have received the greatest attention from those seeking to cloud the science specific to the prevention of HIV. For example, while leading public health organizations, including the World Health Organization (WHO), recognize the effectiveness of needle exchange programs, the United States has maintained a ban on federal funding of needle exchange programs. Likewise, although WHO recently added methadone to its list of essential medicines, methadone remains banned in Russia where HIV is spreading rapidly among injection drug users. Further, despite a growing body of evidence supporting the effectiveness of supervised injection facilities, the International Narcotics Control Board has consistently criticized countries implementing such facilities, and the Canadian Conservative government recently withdrew national support for research into supervised injection facilities and removed harm reduction strategies from its new "AntiDrug Strategy."

Efforts to undermine the science specific to HIV prevention for injection drug users are becoming increasingly sophisticated. One new and worrisome trend is the creation of internet sites posing as open-access, peer-reviewed scientific journals. One such example, funded by the Drug Free America Foundation, contains a review of the research supporting needle exchange program and declares that the "effectiveness of NEPs [needle exchange program] to reduce HIV among IDUs [injection drug users] is overrated;" it further claims that the WHO position on needle exchange programs "is not based on solid evidence."

The global HIV epidemic among injection drug users warrants swift and decisive action that is informed by the best available evidence. According to the Global HIV Prevention Working Group, approximately half of new HIV infections between 2007 and 2015 could be averted with widespread scale-up of evidencebased HIV prevention programs. ${ }^{1}$ In order to meet this target, health policies, and the actions that flow from them, must not be undermined by those working to manufacture uncertainty when the evidence and path forward are clear.

\section{Thomas Kerr PhD \\ Evan Wood MD PhD \\ Research scientists \\ British Columbia Centre for \\ Excellence in HIV/AIDS \\ Vancouver, BC}

\section{REFERENCES}

I. The Global HIV Prevention Working Group. Bring ing HIV prevention to scale: an urgent global priority, 2007. Available: www.globalhivprevention.org /reports.html (accessed 2008 Feb I9).

2. Politics, spin, and science. Lancet 2004;364:1994.

3. Union of Concerned Scientists. Smoke, mirrors and hot air: How ExxonMobil uses Big Tobacco's tactics to manufacture uncertainty on climate science. Cambridge (MA): The Union; 2007. Available: www.ucsusa.org/assets/documents/global_warming lexxon_report.pdf (accessed 2008 Feb I9).

4. Käll K, Hermansson U, Amundsen E, et al. The effectiveness of needle exchange programmes for HIV prevention - a critical review. The Journal of Global Drug Policy and Practice 2007;1:3.

Have you got an opinion about this article? Post your views at www.cmaj.ca. Potential Salon contributors are welcome to send a query to salon@cma.ca. 